\title{
Geomorphological and Environmental changes in West- ern Greece: a remote sensing perspective
}

\author{
EMMANUEL VASSILAKIS ${ }^{(1)}$ \& EFTHIMIA VERYKIOU - PAPASPYRIDAKOU ${ }^{(1)}$
}

\begin{abstract}
Several rapid geomorphological changes can be detected on the landscape of western Greece since the area is adjacent to the highly active Hellenic trench, where major geodynamic phenomena occur. At this part of the Hellenides, various active structures have been affecting the shallow layers of the overriding plate, due to tectonic movements and in some cases gypsum diapirism. Additionally, lots of environmental implications have been reported since a significant amount of development infrastructure is still being constructed in this area for more than the last twenty years, affecting the slower physical ongoing processes. The outcropping erodible lithologies of flysch in conjunction with the existence of high energy rivers reveal a rapidly evolving area with dynamic topography, which can be identified by using the appropriate methodologies. Remote sensing techniques prove to be the ideal way to locate changes at the physical geography of the studied area, especially when multitemporal interpretation is implemented. In this paper we try to locate and analyze these changes by using medium resolution satellite images (Landsat TM and ETM+) of different temporal periods (1992, 2000 and 2005). After special interpretation of the acquired remote sensing images, which involves detailed co-registration and spectral analysis, the identified changes can be temporally categorized between the three acquisition dates. The methodology requires the compilation of new separate datasets, one for each spectral channel from the three Landsat images, in order to detect changes in the absorption and reflection spectra for specific bandwidths. The results show that many parts of the river valleys and the main land surface seem to have been violently altered in several parts and also significant coastal changes have been detected along the deltaic fans of Evinos and Mornos rivers, during the 13-year observation period between 1992 and 2005.
\end{abstract}

Keywords: remote sensing, physical geography, multi-temporal observations.

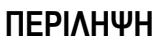

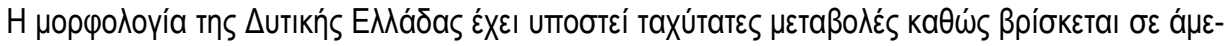

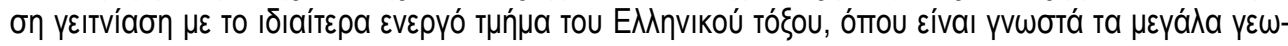

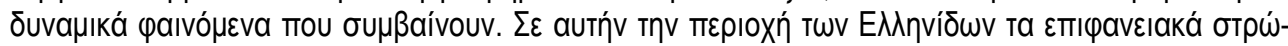

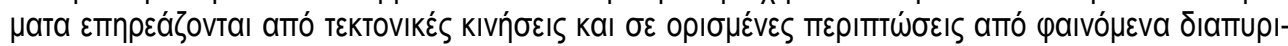

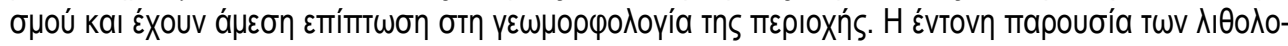

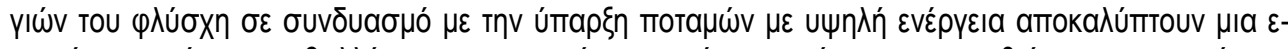

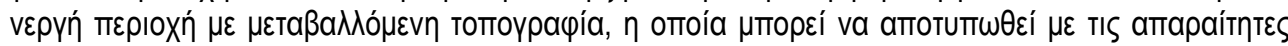

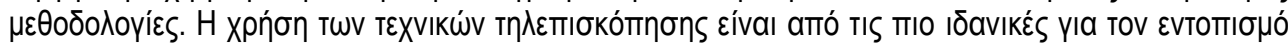

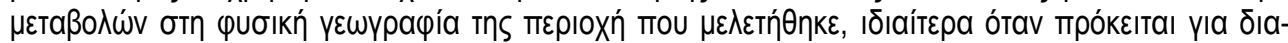

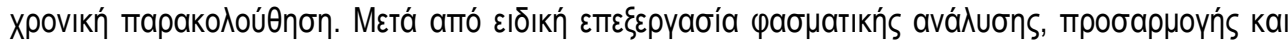

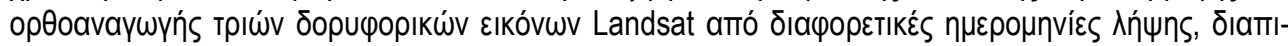

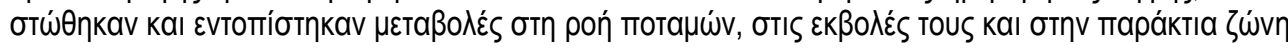

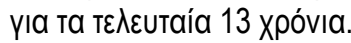

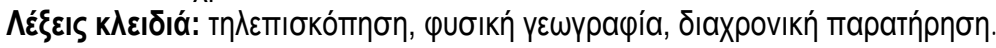

${ }^{1}$ Dpt of Geography \& Climatology, evasilak@geol.uoa.gr, verikiou@geol.uoa.gr 


\section{INTRODUCTION}

Infrastructure development within the western part of Greece is an on going project for more than the last two decades. A large number of dams were already in full operation and a new one was constructed during this period, causing additional environmental and geomorphological changes not only at the wider areas of the artificial lakes but in many cases along the downstream valleys.

The upgrading of transportation quality was a serious point of discussion among the authorities, as formerly there was no uninterrupted highway that connected mainland Greece in the north with the Peloponnesus in the south, since the Gulf of Corinth interrupted the land continuity (Figure 1). Transportation across the western part of the gulf consisted of small ferries completing the route between Rio (mainland Greece) and Antirio (Peloponnesus). This distance, of not longer than two kilometres, was covered by a ferry in about 15 minutes, not including the time for embarkation and disembarkation, but only during adequate weather conditions.

The Gulf of Corinth is one of the most rapidly spreading rifts in the world, generating large and disastrous earthquakes (Jackson et al., 1982, Evangelidis et al. 2008, Gaki-Papanastassiou et al. 1996). Thus, one of the main arguments against construction of a bridge across the gulf was the high seismic potential of the area, which is related to its rapid expansion, determined by GPS techniques to be an average of $18 \pm 2$ $\mathrm{mm} / \mathrm{yr}$ in an approximately north-south direction across the gulf (Briole et al. 2000, Avallone et al. 2004, Bernard et al. 2006, Cianetti et al 2008). New construction techniques allowed for design of the Rio-Antirio Bridge, which was structurally supported by different fault blocks. Its design allowed the bridge to remain intact during future differential movements of the fault blocks (Parcharidis et al. 2009). The bridge was finally completed in 2004, providing a modern alternative highway along the western part of Greece.

The major constructions planned in this area forced the need for material and the least expensive solution was the foundation of new quarries in adjacent sites, which also caused additional environmental alterations (Vassilakis, 2010). In this paper we use remote sensing techniques to detect and locate any changes caused in this area for the last twenty years and an effort was made to assign any of these at specific construction sites.

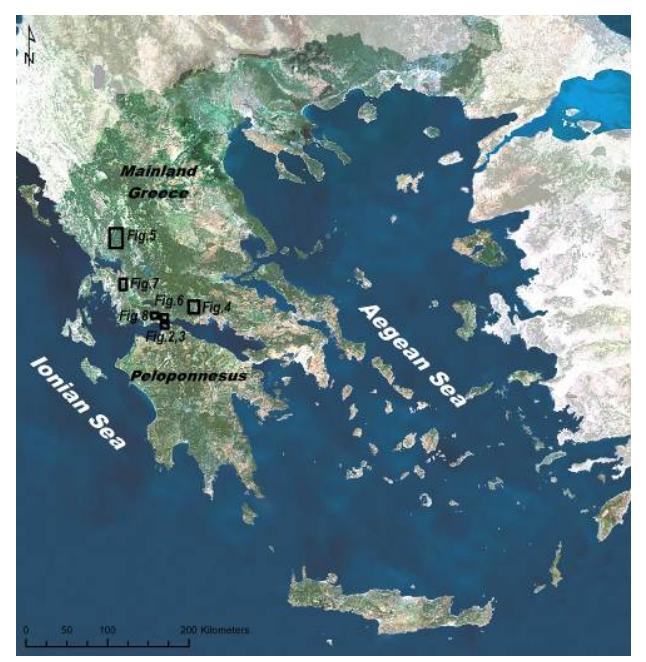

Fig. 1: Location map of the areas mentioned in the text. Fig. 2,3 refers to the area of Rio-Antirio, Fig. 4 refers to the area of Mornos Lake, Fig. 5 refers to Arachthos Lake, Fig. 6 refers to Evinos Lake, Fig. 7 refers to Amvrakia Lake and Fig. 8 refers to a quarry expansion site.

\section{DATA INTERPRETATION}

The satellite images used for detecting the implications caused by the large construction sites and possible environmental changes were captured during several time periods beginning in 1992 and ending in 2005. They cover most of the area that was affected by the development of new and older infrastructure, as described in the introduction. The image processing employed in this study includes atmospheric corrections, co-registration of images and creation of multi-temporal data constructed by creating new datasets for every spectral channel.

False color composite images reveal environmental changes not only where the construction sites are located but also in the coastal areas of the artificial lakes due to the water fluctuation. Higher resolution images were used to increase the spatial resolution of the color com- 
posites, accomplished by merging high resolution images with lower resolution images (Welch \& Ehlers, 1987, Rigol \& Chica-Olmo, 1998) for better evaluation and quantification of the environmental alterations.

The first scene was acquired by the Thematic Mapper sensor (TM), placed on board the Landsat 5 satellite, on September 2, 1992, and consists of path 184 and row 33. Processing begins with geometric ortho-rectification in Universal Transverse Mercator (UTM) projection (zone $34 \mathrm{~N}$ ) by including, in the correction procedure, a highly detailed DEM with 25 meters pixel size (Pouncey et al., 1999). The latter was produced by digitizing topographic map contours at a scale of 1:50,000. Subsequently, a dataset with 1123 columns and 577 rows was created; this covered only a part of the total scene and corresponds to the study area.

The same procedure and dimensions were also applied to two other datasets, one derived from a Landsat 7-ETM+ (Enhanced Thematic Mapper) acquired on June 28, 2000 and another from a Landsat 7-ETM+ acquisition on August 13, 2005. All Landsat data were downloaded from U.S. Geological Survey (USGS) Earth Resources Observation and Science (EROS) Center. The last two datasets were ortho-rectified by using the image to image methodology and taking as reference dataset, the oldest one having the same DEM for altitude reference.

High resolution air photographs of 1996 were also used for larger scale observations with the highest possible accuracy and were imported in a geo-database for further study along with the other data. After these data were ortho-rectified, a mosaic was produced and finally registered to the Landsat 5 ortho-corrected dataset, which was used primarily as the referencing image. The co-registration procedure of all datasets was successful since the RMS error was calculated less than 0.5 pixels either in $X$ or $Y$ geographic axis.

Effects of the atmosphere on remotely sensed data are not considered "errors" because they are part of the signal received by the sensing device. However, it is very important to remove atmospheric effects, especially on visible channels, as it has been noted that the at- mospheric contribution to the radiance received by a satellite forms a much greater percentage of the radiance leaving the target area, than in the case of infrared (Cracknell \& Hayes, 1991). Because this study is focused on detecting changes in a specific region through time, the main analytical tool relies on ground measurements made over time. Therefore it is very important to correct the radiance values recorded by the sensor for the effects of the atmosphere (Mather, 1994). The technique that was applied on the Landsat series of datasets was based on the minimum digital number of the middle infrared band 7 for each dataset (Hadjimitsis et al., 2004).

In general, when images contain areas of low reflectance, such as clear water bodies and deep shadows caused by extreme relief discontinuities, the corresponding pixels have values very close to zero, especially in the middle infrared band 7 of the Landsat TM and ETM+ sensors. Considering that a water body has virtually no reflection, even at shorter wavelengths such as band 4 or band 5 , the digital number of a pixel representing deep sea water in band 7 should not be significantly larger than zero (Lillesand \& Kiefer, 1994). If it is larger than zero, then the non-zero digital number is due to atmospheric effects. This enables one to identify the effects of the atmosphere over large water bodies. The existence of the large water bodies in the Gulf of Patras west of the study area, and the Gulf of Corinth east of the study area, are thus very useful for calculating atmospheric corrections. After computing the statistics over each band of every dataset, the histogram minimum value for band 7 was calculated. This value was subtracted from the digital number arrays of the other bands of the same dataset and the result was a new array with digital numbers shifted towards the zero value, and presumably representing data with atmospheric corrections. The statistics for every single band were updated and the histograms were saved.

\section{METHODOLOGY}

The acquisition dates of the three Landsat images used for the multi-temporal interpretation were almost ideal for the purpose of this study 
because nearly all of them were captured during the summertime (late June to early September) when the local weather conditions are similar

The multi-temporal analysis procedure begins with the compilation of six datasets, each one containing a single spectral channel from the three Landsat images. Each of these datasets contains three bands with the same Landsat spectral channel for each acquisition date. The thermal infrared channels of the Landsat 5 and Landsat 7 were not used because the spatial resolution varies for the TM and ETM+ sensors and the thermal reflectance cannot be considered identical throughout long time periods. Thus, the interpretation continues separately for each spectral channel in order to detect changes in the absorption and reflection spectra for specific bandwidths. Subsequently, six pseudo chromatic images were produced by using the earliest data in the red channel (R-1992), the latest data in the blue channel (B-2005) and the intermediate data in the green channel (G-2000) (Figure 2).

The resultant color composite images for every channel are presented in such a way as to locate the areas with high pixel values for each of the red, green or blue colors. In these cases, the earth's surface changed significantly from one acquisition date to the next. These observations proved to be quite difficult to obtain from images collected during the intermediate observation period (2000), as restoration works for the altered land coverage (river flow, forest fire, quarry operations etc.) could have taken place before the capturing date of the last satellite image (2005).

In detail, areas colored nearly pure red in the pseudo-chromatic images reveal areas that suffered significant change after September 2, 1992 and remained unchanged until August 13, 2005. The almost pure green areas represent changes on the earth's surface which happened in the time window between November 3, 1992 and June 28, 2000; with the provision that before and after these dates the land coverage should be more or less similar, or at least the spectral attitude of the area should be the same. If full and successful environmental restorations of an altered area have occurred, these areas would appear as green in each of the six datasets. Otherwise the restoration could not be characterized as completely successful, because the spectral attitude of the rehabilitated area is not the same before and after the environmental alteration. Finally, nearly pure blue areas represent change that happened after June 28, 2000 and before August 13, 2005.
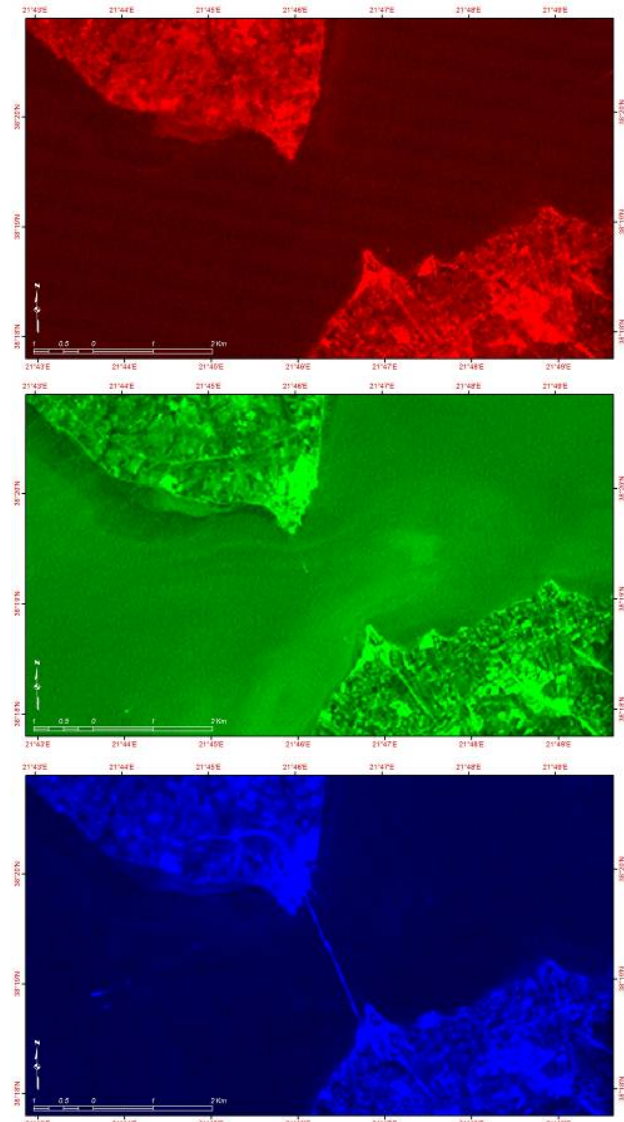

Fig. 2: Landsat-TM Band 1 ( 0.45 to $0.52 \mu \mathrm{m})$ images of the area of Rio-Antirio Bridge, each one representing the three capturing dates, were assigned by the three basic colors (R-1992/B-2000/G-2005). The major changes refer to the bridge as well as the road infrastructure on both sides of the land area (Peloponnesus to the south and mainland Greece to the north). 


\section{CHANGE DETECTION RESULTS}

Rio-Antirio Bridge

In the pseudo-color image produced from band 1 , the most spectacular change is represented by a blue linear feature connecting mainland Greece to the Peloponnesus; this is the Rio-Antirio cable bridge completed in 2004 and inaugurated just before the Athens Olympic Games. The blue color indicates that this bridge did not exist when the first two satellite images were acquired but did exist when the third satellite image was acquired (Figure 3). Thus it is clearly depicted on the 2005 Landsat image which has been assigned to the blue channel. Additionally, the new road junctions on both sides of the gulf next to the bridge are also blue.

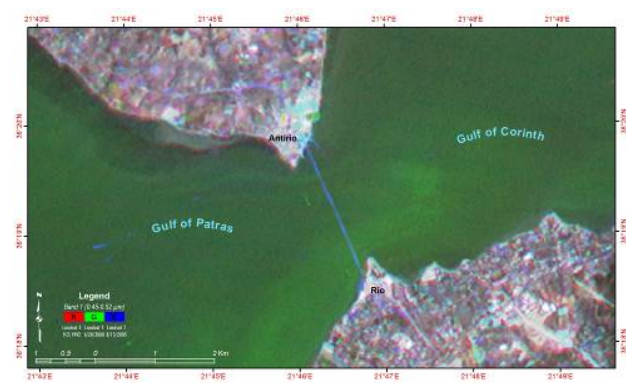

Fig. 3: False color multi-temporal image, derived from the figure 2 single band images, of the recently constructed Rio-Antirio bridge.

\section{Artificial lakes}

The methodology revealed the change of the water level in several dams throughout western Greece. In general, the variation of the volume in such water bodies does have great impact to the environment and therefore it is highly important to follow and in some cases quantify these changes. It should be mentioned that Band 4 was used for these multi-temporal images since the absorbance in clear waters of the near infrared spectra is very high.

As it was observed, the water level in Mornos Lake was at its highest altitude during 2000. This is quite clear as green pixels create a thin zone around the lake, which defines the water level during the capturing date of the second satellite image that is June 2000 (Figure 4).
The period between 1992 and 2000 was quite refreshing for the operation of the dam as the water level was apparently rising up. The red pixels around the lake are surrounded by a thinner stripe of green ones and this yields a rising water level for these years. Since 2000 and until August 2005 the water level dropped down dramatically and this is visualised in the multi temporal image. The dark pixels in the lake refer to the area which is continuously covered with water throughout the period from 1992 till 2005. Hence, during 2005 the lake was at its lowest altitude as we cannot identify any bluish pixels around the lake but only red (for 1992) and green (for 2000).

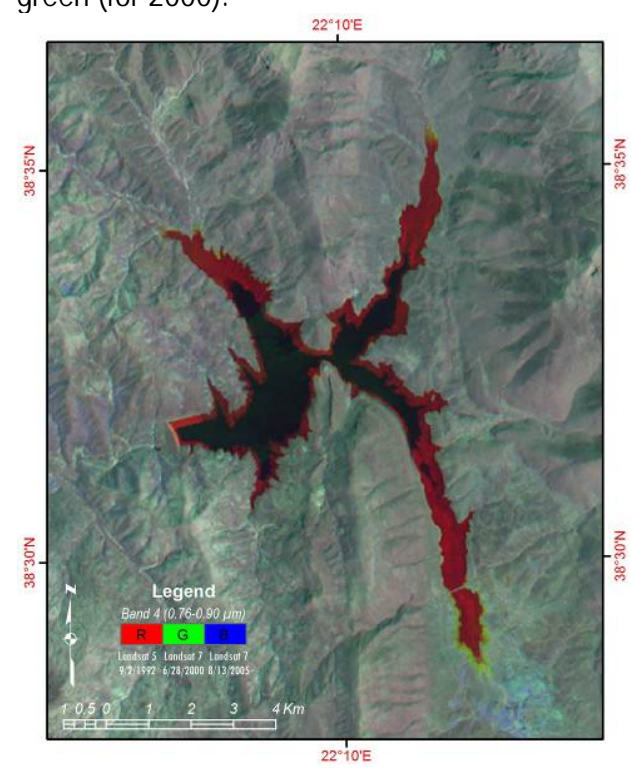

Fig. 4: Multi-temporal image interpretation for Mornos artificial lake. The water body seems to have been shrunk significantly during a 5-year period.

The case of Arachthos artificial lake is not very similar with the one of Mornos which was mentioned before. The dark pixels which represent the area covered with water at all times from 1992 till 2005 are almost everywhere. There are only few pixels with green and red colours and this means that either the water level had no variations throughout the study period or the relief of the banks around the lake is quite high. The latter seems to be the case here as in a closer look of the produced image 
there are thin red and green stripes of pixels at the middle part of the lakes' coastal zone (Figure 5). This means that the water level fluctuated but the lake did not get wider as the slopes around the biggest part were almost vertical. In any case, the highest water level seems to happen during 2000, rising up since 1992 and eventually dropped down until 2005.
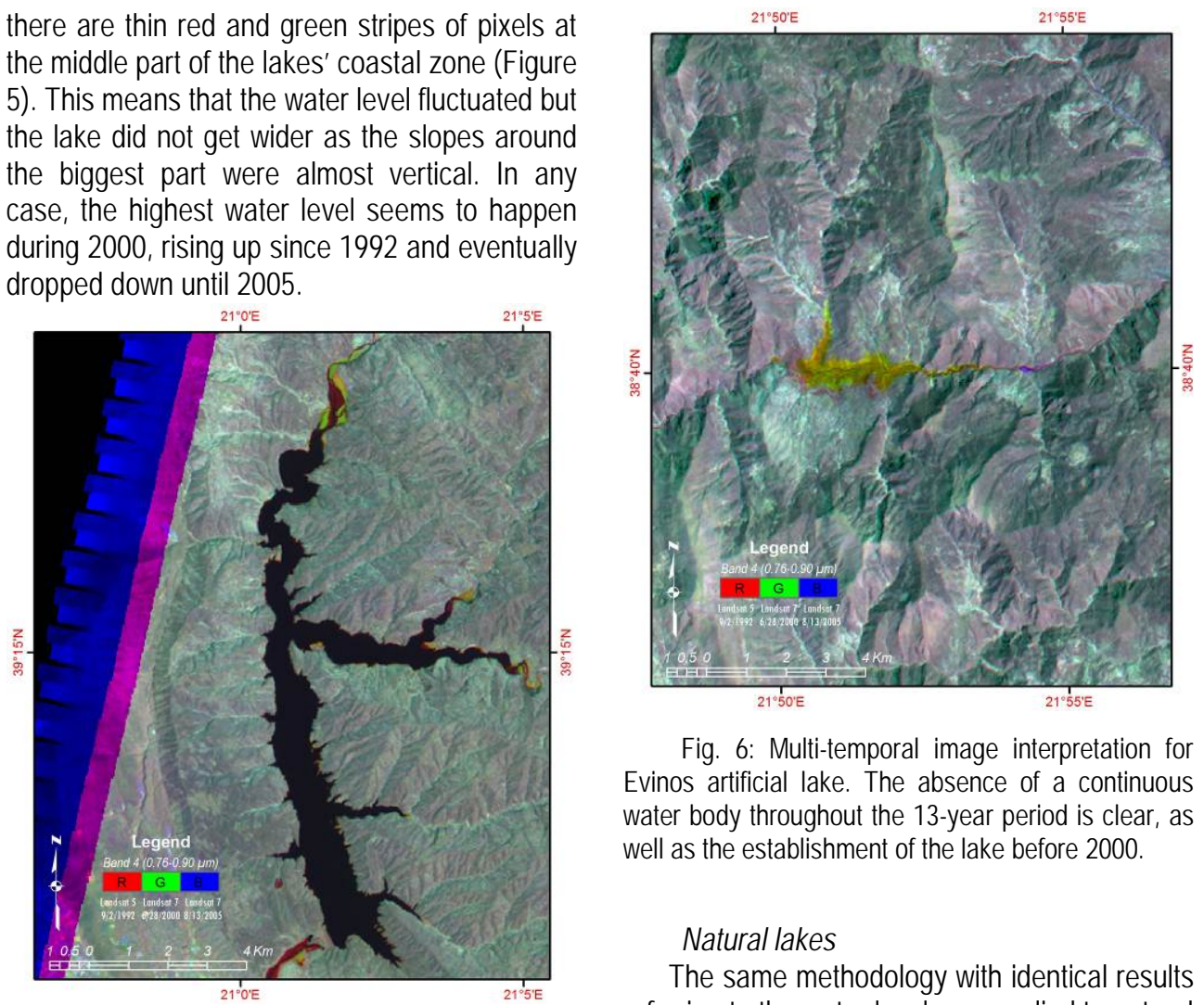

Fig. 6: Multi-temporal image interpretation for Evinos artificial lake. The absence of a continuous water body throughout the 13-year period is clear, as well as the establishment of the lake before 2000 .

\section{Natural lakes}

The same methodology with identical results

Fig. 5: Multi-temporal image interpretation for Arachthos artificial lake. The water body does not seem to have suffered significant changes.

The dam on the Evinos River begun to be constructed in 1992, it was completed in June 2001 and the lake was filled up in October 2002. Therefore in our false composite interpretation there are no dark pixels which would represent the existence of a single water body from 1992 till 2005.

On the other hand the satellite image of 2000 show an artificial lake starting to take its place upstream from the dam area and in the multi-temporal image it is represented by greenish pixels (Figure 6). The bluish pixels at the easternmost side of the lake show that the water level was still rising for the next five years until 2005 , which is the capturing date of the most recent Landsat image that was included in our interpretation. referring to the water level was applied to natural lakes of western Greece. A representative example is the case of Amvrakia Lake. The surrounding physical relief of this lake is quite peculiar since the western banks of the lake consist of almost vertical slopes in contradiction to the eastern banks where the relief is relatively low. Therefore, the variation of the water level would be more clearly identified at the eastern coastal zone where the width of the exposed lake bottom, in a case of a dropped water surface, would be represented by a larger number of pixels.

After the production of the false color composite image regarding the multi-temporal interpretation a large number of dark pixels were identified, which represent the existence of water for the whole period of study (1992-2005). The lack of green pixels around the lake led us to the conclusion that there was no significant change in the volume of the water body after 2000. On the contrary, the red stripe of pixels, which represent the water level during 1992, 
yield that there was a dramatic dropdown of the lake's surface between 1992 and 2000. As it was mentioned before, the red pixels cover the eastern banks of Amvrakia Lake and not the western ones because of the relief contrast.

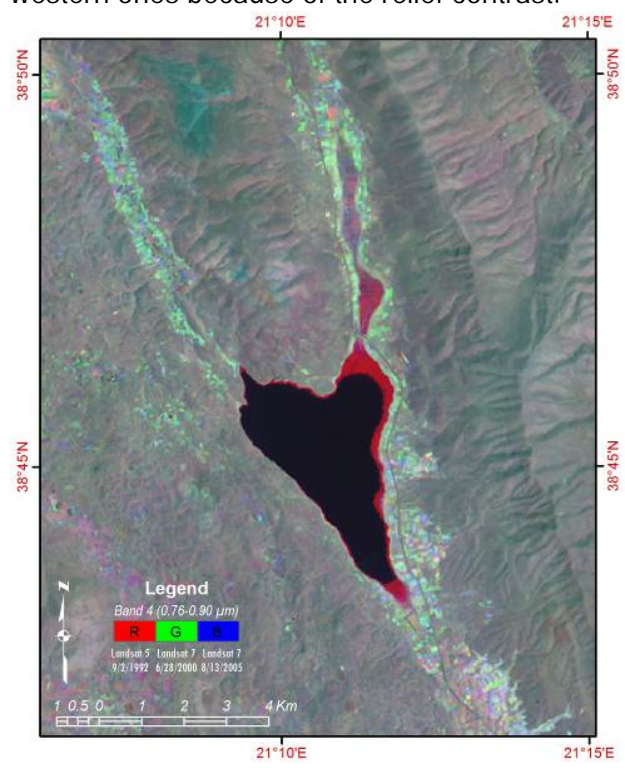

Fig. 7: Multi-temporal image interpretation for Amvrakia natural lake. The drop down of the water level during the 13-year period is clear only at the eastern banks of the lake, since along the almost vertical slopes at the western banks no red pixels can be identified.

\section{Quarry sites}

The multi-temporal interpretation of the Lansat images enhanced the ability to detect more changes on the land surface too, especially where natural vegetation was replaced by bare soil or rock. It was more than certain that geometrical shapes of different colored areas in the pseudo chromatic image products were due to manmade alterations of the earth surface and in many cases the environmental implications are quite destructive. In such cases and when the spatial resolution of the used satellite images does not meet the quality of the observations, higher resolution remote sensing data are used. In the case of this paper, we used a dataset of air photographs (acquired in 1996 with 1m spatial resolution) and a Quickbird panchromatic image (acquired in 2002 with $0.6 \mathrm{~m}$ spatial resolution) (Figure 8).
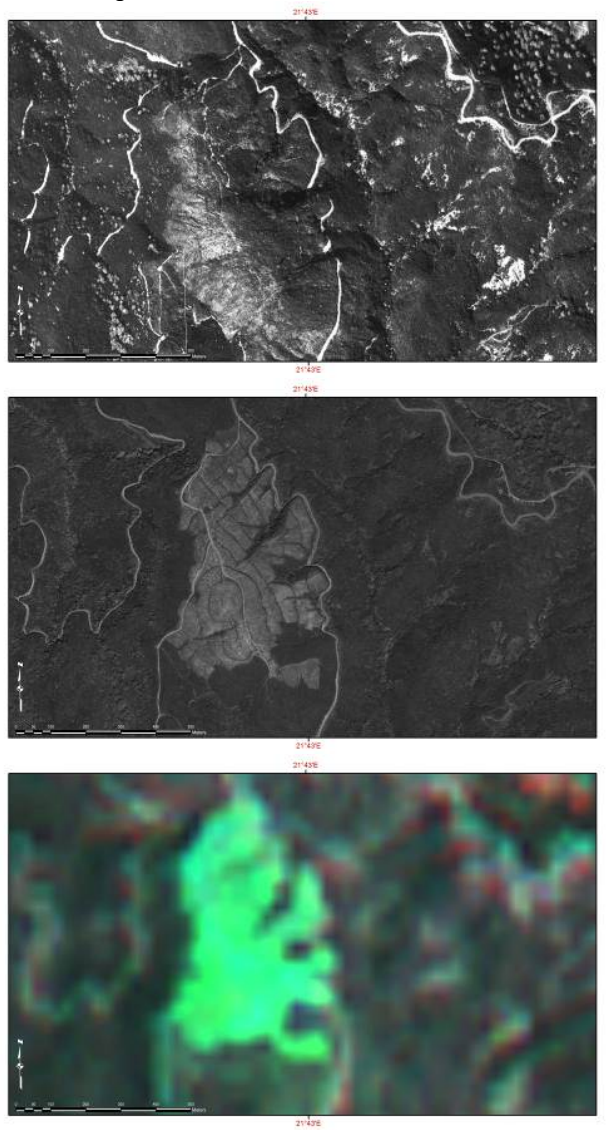

Fig. 8: The development of a quarry site as observed by the air photographs of 1996 (up), a Quickbird image of 2002 (middle) and the multi-temporal false composite Landsat-TM (band 7) image interpretation (1992-2005).

The detail study and careful co-registration of all the provided data led us to the conclusion that a big quarry was developed sometime after 1992 but before 1996 as the air photographs show its operation at a very early stage. The quarry works have expanded, gradually causing a decrease in the forest vegetation that used to cover the surrounding area. During 2003 the quarry seems to have reached the top of its excavation as new roads and steep terraces have been constructed and are clearly identified in the Quickbird image. There is also a smoothing of the relief as shown in the 1996 high reso- 
lution air photographs; this is not consistent with the exposure of the steep quarry terraces that are clearly visible in the Quickbird image. Restoration of the quarry site must have begun between 2002 and 2005, by covering the quarry with vegetation because there is no blue in the false color image at this location, indicating that the reflectance was not that of bare soil when the latest Landsat image was acquired.

\section{CONCLUSIONS}

This paper highlights the important role that analysis of multispectral satellite data can play in the identification of surface alterations related to human activity and natural processes. In some cases high resolution satellite images will also be needed to quantify the spatial extent of surface alterations, but multispectral data, at either medium or high spatial resolution, will remain the key in identifying the existence and timing of changes to the earth's surface environment.

The multi-temporal image interpretation technique allows for the identification and, in many cases, the quantification of these environmental effects. The availability of a dense time series of remote sensing multispectral data provides an opportunity to identify changes on the earth's surface. In some cases, these may signal major environmental changes of a serious nature and indicate the need for preventative measures to avoid an environmental disaster.

\section{REFERENCES}

Avallone, A.; Briole, P.; Agatza-Balodimou, A.M.; Billiris, H.; Charade, O.; Mitsakaki, C.; Nercessian, A.; Papazissi, K.; Paradissis, D.; Veis, G. Analysis of eleven years of deformation measured by GPS in the Corinth Rift Laboratory area. Comptes Rendus Geosciences 2004, 336, 301-311.

Bernard, P.; Lyon-Caen, H.; Briole, P.; Deschamps, A.; Boudin, F.; Makropoulos, K.; Papadimitriou, P.; Lemeille, F.; Patau, G.; Billiris, H.; Paradissis, D.; Papazissi, K.; Castarede, $H_{\text {.; }}$ Charade, O.; Nercessian, A.; Avallone, A.; Pacchiani, F.; Zahradnik, J.; Sacks, S.; Linde, A. Seismicity, deformation and seismic hazard in the western rift of Corinth: New insights from the Corinth
Rift Laboratory (CRL). Tectonophysics 2006, 426, 7-30.

Briole, P.; Rigo, A.; Lyon-Caen, H.; Ruegg, J.C.; Papazissi, K.; Mitsakaki, C.; Balodimou, A.; Veis, G.; Hatzfeld, D.; Deschamps, A. Active deformation of the Corinth rift, Greece: Results from repeated Global Positioning System surveys between 1990 and 1995. J. Geophys. Res. 2000, 105, 25605-25625.

Cianetti, S.; Tinti, E.; Giunchi, C.; Cocco, M. Modelling deformation rates in the western Gulf of Corinth: rheological constraints. Geophys. J. Int. 2008, 174, 749-757.

Cracknell, A.; Hayes, L. Introduction to Remote Sensing; Taylor and Francis: London, UK, 1991; p. 293.

Evangelidis, C.P.; Konstantinou, K.I.; Melis, N.S.; Charalambakis, M.; Stavrakakis, G.N. Waveform Relocation and Focal Mechanism Analysis of an Earthquake Swarm in Trichonis Lake, Western Greece. Bull. Seismol. Soc. Amer. 2008, 98, 804-811.

Gaki-Papanastassiou, K.; Papanastassiou, D.; Maroukian, H. Geomorphic and archaeological-historical evidence for past earthquakes in Greece. Ann. Geofis. 1996, 39, 589-601.

Hadjimitsis, D.G.; Clayton, C.R.I.; Hope, V.S. An assessment of the effectiveness of atmospheric correction algorithms through the remote sensing of some reservoirs. Int. J. Remote Sens. 2004, 25, 3651-3674.

Jackson, J.A.; Gagnepain, J.; Houseman, G.; King, G.; Papadimitriou, P.; Soufleris, C.; Virieux, J. Seismicity, normal faulting, and the geomorphological development of the Gulf of Corinth (Greece) the Corinth earthquakes of February and March 1981. Earth Planet. Sci. Lett. 1982, 57, 377-397.

Lillesand, T.; Kiefer, R. Remote Sensing and Image Interpretation, 3th ed.; Wiley \& Sons: New York, NY, USA, 1994; p. 750.

Mather, P. Computer Processing of RemotelySensed Images: An Introduction; Wiley \& Sons: West Sussex, UK, 1994; p. 352.

Parcharidis, I.; Foumelis, M.; Kourkouli, P.; Wegmuller, U. Persistent Scatterers InSAR to detect ground deformation over RioAntirio area (Western Greece) for the peri- 
od 1992-2000. J. Appl. Geophys. 2009, 68, 348-355.

Parcharidis, I.; Metaxas, C.; Vassilakis, E. Earth observation data and geographical information system (GIS) techniques for earthquake risk assessment in the western Gulf of Corinth, Greece. Canad. J. Remote Sens. 2006, 32, 223-227.

Pouncey, R.; Swanson, K.; Hart, K. ERDAS Field Guide, 5th ed.; ERDAS Inc: Atlanta, GA, USA, 1999; p. 671.

Rigol, J.; Chica-Olmo, M. Merging remotesensing images for geologicalenvironmental mapping: application to the Cabo de Gata-Nvjar Natural Park, Spain. Environ. Geol. 1998, 34, 194-202.

Vassilakis, E. Remote Sensing of Environmental Change in the Antirio Deltaic Fan Region, Western Greece. Remote Sensing 2010, 2(11), 2547-2560.

Welch, R.; Ehlers, W. Merging Multiresolution SPOT HRV and Landsat TM Data. Photogramm. Eng. Remote Sensing 1987, 53, 301-303. 